\title{
Timing of breeding carries over to influence migratory departure in a songbird: an automated radiotracking study
}

\author{
Greg W. MitchelI ${ }^{1^{*}}$, Amy E. M. Newman ${ }^{1}$, Martin Wikelski ${ }^{2}$ and D. Ryan Norris ${ }^{1}$ \\ ${ }^{1}$ Department of Integrative Biology, University of Guelph, Guelph, ON N1G 2W1, Canada; and \\ ${ }^{2}$ Department of Migration and Immuno-ecology, Max Planck Institute for Ornithology, Radolfzell 78315, Germany
}

\begin{abstract}
Summary
1. Determining how events interact across stages of the annual cycle is critical for understanding the factors that affect individual fitness. However, there is currently little information detailing how breeding events influence migratory behaviour.

2. Using an automated digital telemetry array and an isolated island-breeding population of Savannah sparrows Passerculus sandwichensis, we provide the first direct evidence that the timing of breeding events carries over to influence the timing of migration in a songbird and assess for the first time how weather conditions on the breeding grounds also affect departure dates.

3. Date of migratory departure between September and October was strongly influenced by date of breeding completion in adults and fledging date in juveniles from June to July.

4. With respect to weather, adults departed during the first half of high-pressure systems, while juveniles departed throughout the entirety of high-pressure systems (including rainy evenings on the western edge of systems).

5. By combining both ecological and weather data, we could explain almost all variation in departure date for adults $(95 \%)$, but weather conditions were not a good predictor of departure date for juveniles.

6. Our results provide strong evidence that the timing of breeding events is an important driver of migration timing and that exact departure dates are fine-tuned according to local weather conditions in adults, but not in juveniles.
\end{abstract}

Key-words: carry-over effects, early-life events, life-history stages, life-history trade-offs, migration, movement, radiotelemetry, songbirds, telemetry array

\section{Introduction}

The annual cycle of vertebrates is organized into a series of life-history stages, each characterized by a unique combination of morphological, physiological, and behavioural traits that maximize fitness in response to predictable fluctuations in environmental conditions (e.g. seasonality; Jacobs \& Wingfield 2000; Dänhardt \& Lindtröm 2001; Wingfield 2008). Determining how events or processes interact between the stages of the annual cycle is critical for understanding the factors that influence individual fitness and population dynamics (Norris \& Marra 2007; Harrison et al. 2011). One common mechanism through which events in one stage carry over to affect individual success in a subsequent stage is through timing, where delays in an earlier stage cause a mismatch between actual and optimal timing in subsequent

*Correspondence author. E-mail: mitchelg@uoguelph.ca stages (Harrison et al. 2011). For example, mule deer that delay autumn migration are more likely to experience food shortages en route as a result of deteriorating weather conditions (Monteith et al. 2011), and late migrating monarch butterflies Danaus Plexippus in the spring have increased risk of mortality from high temperatures in Texas and their offspring are less likely to survive (Malcolm, Cockrell \& Brower 1987).

In migratory birds, the timing of autumn migration is hypothesized to affect individual survival because late departing individuals may be more likely to encounter inclement weather on the breeding grounds or en route and may experience lower resource availability at stopover sites as a result of resource suppression by earlier migrants (Newton 2006, 2007, 2008). At the broadest temporal scale, timing of migration is controlled by a heritable endogenous circannual rhythm (Berthold 1996; Gwinner \& Helm 2003; Gwinner 2008). At a finer scale, correlations between fledging 
date and the onset of migratory activity in the laboratory (Pulido et al. 2001; Pulido \& Widmer 2005), broad indirect correlations between the average timing of events on the breeding grounds and the average timing of migration at stopover sites for different study populations (Bojarinova, Rymkevich \& Smirnov 2002) and correlations between average timing of breeding and average date of last capture measured across years (Morton \& Pereyra 1994) suggest departure dates can be modified by an individual's breeding or natal history. At an even finer temporal scale, studies at stopover sites suggest timing of migration is controlled by the availability of favourable weather conditions for migration (Åkesson \& Hedenström 2000; Sapir et al. 2011). However, to date, there has yet to be a direct assessment of how the timing of breeding events and the availability of favourable weather conditions for migration influence the timing of migration from the breeding grounds in free-living songbirds.

Using a digital radiotelemetry array and detailed reproductive information collected over 2 years, we examined how the timing of breeding events influenced the timing of migratory departure in adult and juvenile Savannah sparrows Passerculus sandwichensis inhabiting a small isolated island. We hypothesized that date of migratory departure was dependent on date of breeding completion or fledging date because individuals require a set amount of time following these events to prepare for migration (e.g. to moult; Newton 2008). We predicted a positive relationship between date of migratory departure with both date of breeding completion and fledging date in adults and juveniles, respectively. We also examined the hypothesis that residual variation in date of departure not accounted for by breeding variables, body condition, age or year, could be accounted for by variation in weather. We predicted that individuals departing earlier than expected did so because they encountered favourable conditions for migration and that individuals departing later than expected did so because they encountered unfavourable weather conditions up until the evening they departed.

\section{Materials and methods}

\section{STUDY SITE AND SPECIES}

Fieldwork was conducted on Kent Island, an isolated 80-ha island in the Bay of Fundy, New Brunswick, Canada $\left(44^{\circ} 35^{\prime} \mathrm{N}, 66^{\circ} 45^{\prime} \mathrm{W}\right.$; Fig. 1). We studied a population of migratory Savannah sparrows inhabiting a 10-ha old-field located in the centre of the island. Savanna sparrows are grassland songbirds that breed in the northern United States and across Canada, and primarily winter throughout the southern United States (Wheelwright \& Rising 2008). On Kent Island, median clutch size is four eggs (Wheelwright \& Schultz 1994), and median adult body mass during the breeding period is $20 \mathrm{~g}$ for males and $19 \mathrm{~g}$ for females (Freeman-Gallant 1996). Adults typically begin breeding in late May and fledging generally occurs 26 days after the first egg is laid (Wheelwright \& Rising 2008).

Savanna sparrows on Kent Island represent an ideal population to examine the links between the breeding period and autumn migration for two main reasons. First, variation in the number of clutches per season and moderate nest predation rates resulted in a range of fledging dates (Wheelwright \& Rising 2008). Second, the small size of the

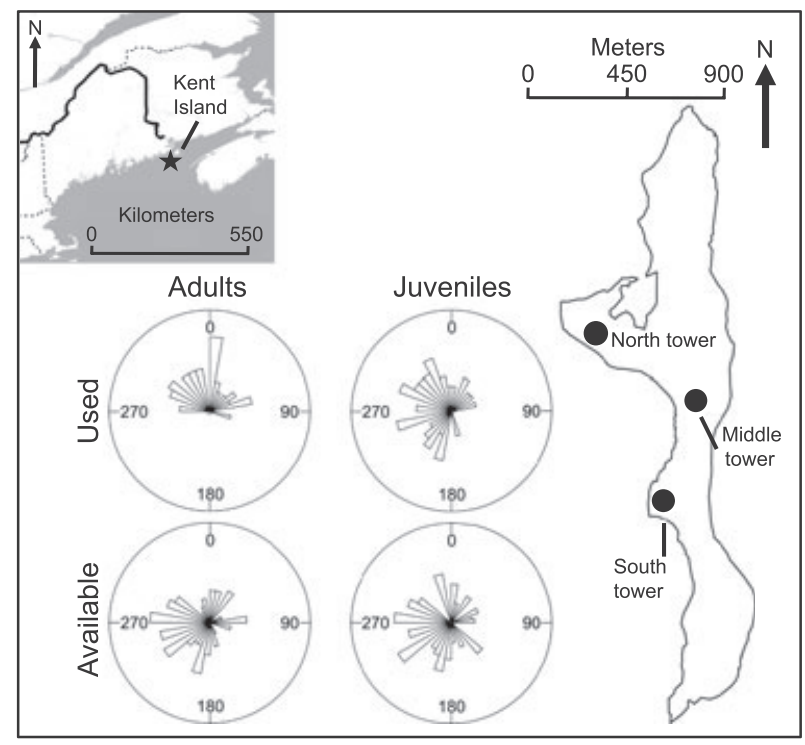

Fig. 1. Location of study site, depiction of Kent Island, and rose-diagrams (circular histograms) illustrating directions of used and available winds for adults and juveniles. Inset: map of south-eastern Canada and the north-eastern United States. The arrow indicates geographic north, the solid line represents the international border and the hatched lines represent state and provincial borders. The star indicates the location of Kent Island. Right: depiction of Kent Island. The arrow indicates north and black circles represent locations of automated telemetry towers. Left: rose-diagrams showing used and available winds (rose-diagrams illustrate the direction from which winds are blowing).

island and its isolation restricted the scope of pre-migratory movements and allowed us to be confident that departures from the island represented initial migratory movements.

\section{BREEDING PERIOD}

Nests were located between 30 May and 25 July in 2009 and 2010 by observing adult females during the nest-building and incubation stages. Unbanded adults were captured on their breeding territories with mist-nets and subsequently banded. At the time of capture, tarsus length $( \pm 1 \mathrm{~mm})$ was measured according to Pyle (1997), and a top-loading electronic balance was used to measure mass $( \pm 0 \cdot 1 \mathrm{~g})$. Sex was assigned based on the presence or absence of a brood patch or cloacal protuberance and was later confirmed with observations of breeding behaviour (e.g. singing males, incubating females, copulation and mate-guarding). Timing of breeding completion was calculated as the fledging date of the last nest in a season +14 days, which represents the average time until parental independence (Wheelwright \& Rising 2008). In the event that an individual's last nest attempt failed ( $n=5$ ), we defined date of breeding completion as the last day for which the nest was known to be active (nests were visited every 2 days to monitor nest fate). Nestlings were banded at 7 days of age, and banding date was used as an index of fledging date (which normally occurs 9-11 days following hatch; Wheelwright \& Rising 2008). Tarsus length and mass were measured as described earlier.

\section{PRE-MIGRATORY PERIOD}

Individuals were captured between 01 September and 25 October in 2009 and between 18 August and 20 October in 2010. Each day 
between 07.00 and $17.00 \mathrm{~h}$ AST, 2-3 $50 \times 50 \mathrm{~m}$ quadrants were randomly selected (from 29 in total) without replacement for netting. Upon capture, the same morphological measurements described earlier were taken, and individuals were fitted with small digitally coded radiotransmitters $(0.62 \mathrm{~g}, 62$ days minimum battery life; model NTQB-3-2, Lotek, Newmarket, ON, Canada).

Radiotransmitters were deployed between 1 September and 9 October in 2009 and between 25 August and 29 September in 2010. In both years, the majority of transmitters were deployed prior to 15 September (37 of 42 or $88 \%$ of transmitters deployed in 2009 and 47 of 55 or $85 \%$ of transmitters deployed in 2010). In 2009, 24 adults and 18 juveniles were fitted with radiotransmitters and in 2010, 26 adults and 29 juveniles were fitted with radiotransmitters. Transmitters were affixed to birds using a figure-eight leg-loop harness (Rappole \& Tipton 1991) comprised of elastic thread (mass of harness + adhesive for attachment $=0.08 \mathrm{~g}$; total mass of radio + harness $=0 \cdot 70 \mathrm{~g}$ ). In a recent analysis on the same population, we showed that radiotransmitters had no effect on total body water or the quantity of fat for adults or juveniles during the premigratory period (Rae et al. 2009).

\section{DEPARTURE DATE}

Date of departure was measured using an automated digital telemetry array comprised of three 9.14-m towers (Fig. 1) affixed with four 4-element Yagi antennas. Because radiotransmitters were digitally coded, we assigned all transmitters to one of three VHF radio frequencies. Our scanning cycle ensured that each individual was monitored continuously for $21.6 \mathrm{~s}$ in $64 \cdot 8$-s intervals. Please refer to Supporting Information: Appendix S1 for a detailed description of our telemetry methods, Appendix S2 for detailed predictions regarding age, sex, year, and body condition, and Appendix S3 for a summary of the methods used to estimate body condition at departure.

\section{WEATHER}

Surface wind direction (direction form which winds were blowing relative to geographic north in $10^{\circ}$ intervals), surface wind speed $\left(\mathrm{km} \mathrm{h}^{-1}\right)$ and atmospheric pressure $(\mathrm{kPa})$ were measured hourly at the Grand Manan Weather Station $\left(44^{\circ} 42^{\prime} 43 \cdot 4^{\prime \prime} \mathrm{N} 66^{\circ} 48^{\prime} 06 \cdot 9^{\prime \prime} \mathrm{W}\right.$; $13.6 \mathrm{~km}$ north-west of Kent Island) and were accessed from the Canadian National Climate Information and Data Archive (NCIDA; http://www.climate.weatheroffice.gc.ca, accessed 25 January 2012). Precipitation (raining or not raining), cloudiness $(1=$ clear skies, $2=1 / 10$ th to $4 / 10$ ths cloud cover, $3=5 / 10$ ths to $9 / 10$ ths cloud cover, $4=$ overcast) and visibility $(\max =24 \cdot 1 \mathrm{~km})$ were also collected hourly, but from the Saint John Airport Weather Station $\left(45^{\circ} 19^{\prime} 05 \cdot 0^{\prime \prime} \mathrm{N} 65^{\circ} 53^{\prime} 08 \cdot 1^{\prime \prime} \mathrm{W} ; 110 \mathrm{~km}\right.$ north-east of Grand Manan), and were again accessed from the NCIDA. Given that meteorological measurements were collected every hour, all data were measured within at least half an hour of each departure. See Appendix S4 for detailed predictions related to weather variables.

\section{STATISTICAL MODELS}

All analyses were conduced in R version 2·12 1 (R Development Core Team 2008). For adults, date of departure was modelled using a multiple linear regression model (stats-package; R Development Core Team 2008). Two adults were measured in both years of the study. Exclusion of one randomly selected departure date for each of these individuals did not affect the sign, magnitude or significance of parameter estimates (Table S1), and so all departure dates were retained in the analysed dataset. For juveniles, date of departure was initially modelled using a linear-mixed effects model (nlme-package; Pinheiro et al. 2010) with restricted maximum likelihood estimates of parameter coefficients because we measured departure dates for 12 groups of siblings. Random effects were included for natal nest nested within mother ID to control for covariances among nest mates and siblings; however, a likelihood ratio test indicated that the random effect for natal nest was not significant $\left(\chi_{1}^{2}=1 \cdot 3, P=0 \cdot 248\right)$, and a restricted likelihood ratio test (RLRsim package; Scheipl 2010) indicated that the random effect for natal nest was also not significant $(P=0.217)$. Thus, for parsimony, both random effects were removed from the final model.

Likelihood of departure with respect to weather was modelled using conditional logistic regression models (survival-package; Therneau \& Lumley 2011), which are ideal for situations where the choice set (what is available) varies between individuals (Manly et al. 2002). In our models, the choice set was defined by the residuals from the departure date models. For example, if a bird was predicted to depart on the evening of day 200 but actually departed on the evening of day 206, then this bird's choice set would be the evenings of days 200 through 206. Weather variables for days when birds did not depart were measured at $2 \cdot 1 \mathrm{~h}$ following sunset for adults and $2 \cdot 4 \mathrm{~h}$ following sunset for juveniles. These values represent the median times of departure during the evening for each age group. Again, removal of one randomly selected departure date from each of the two adults that were tracked in both years of the study had little effect on the sign, magnitude or significance of parameter estimates (Table S2). For juveniles, random effects were specified for nest ID and mother ID. In the event that the predicted date of departure was the same as the actual date, the choice set was defined by the departure day and the day immediately preceding departure.

To determine whether the unexplained variation from our departure date models could be accounted for by weather, we used a twostep procedure. First, we assigned a likelihood of departure to each evening in each bird's choice set using our conditional logistic regression models. The evening with the highest likelihood of departure represented our new estimate of departure date. We then regressed these estimates on the observed departure dates to obtain a new $R^{2}$ value. Second, we used a bootstrap procedure to evaluate the significance of the $R^{2}$ values from step one. Specifically, we regressed observed departure dates on randomly chosen departure dates from each bird's choice set and repeated this procedure 10000 times. This allowed us to assess the probability of obtaining an $R^{2}$ value as high or higher than the $R^{2}$ value obtained after accounting for weather.

Significance of parameter estimates and statistical tests for all analyses were evaluated at $\alpha=0 \cdot 05$. Potential curvilinear relationships were assessed prior to model fitting using scatter-plots fitted with loess lines for the linear models and plots of the $25 \%$ quantile midpoints for each predictor vs. the predicted logit values for the conditional logistic regression models (Hosmer \& Lemeshow 2000). Correlations between predictors were evaluated through the variance-covariance matrix of the fitted models ( $r \geq 0.7$ were considered to be highly correlated). Model fit was visually assessed using residual plots. Unless otherwise stated, reported results are for standardized data.

\section{Results}

\section{DEPARTURE DATE}

The average date of breeding completion for adults was 23 July $(\mathrm{SD}=13$ days $)$ in 2009 and 27 July $(\mathrm{SD}=9$ days $)$ in 
2010. Average fledging date for juveniles was 09 July in both years (2009: $\mathrm{SD}=14$ days; 2010: $\mathrm{SD}=11$ days). The average amount of time between when an adult was last captured and when they departed on migration was 17 days $(\mathrm{SD}=8)$ in 2009 and 20 days in 2010 (SD = 12). The average amount of time between when a juvenile was last captured, and when they departed on migration was 15 days $(\mathrm{SD}=8)$ in both 2009 and 2010. Adults departed an average of 77 days $(\mathrm{SD}=12)$ following breeding completion in 2009, and 67 days $(\mathrm{SD}=6$ ) following breeding completion in 2010 . Average date of departure for adults was 4 October $(\mathrm{SD}=11$ days; range $=15$ September-29 October $)$ in 2009 and 8 October $(\mathrm{SD}=7$ days; range $=11$ September -14 October) in 2010. Juveniles departed an average of 88 days $(\mathrm{SD}=15)$ following fledging in 2009 and 78 days $(\mathrm{SD}=12)$ following fledging in 2010. Average date of departure for juveniles was 7 October ( $\mathrm{SD}=11$ days; range $=16$ September-27 October) in 2009 and 27 September $(\mathrm{SD}=11$ days; range $=12$ September-25 October $)$ in 2010. Adults departed significantly later than juveniles in 2010 ( $t$-test: $\left.t_{46}=-2 \cdot 5, P=0 \cdot 015\right)$, but not in 2009 ( $t$-test; $\left.t_{37}=0 \cdot 5, P=0.638\right)$.

\section{ECOLOGICAL AND LIFE-HISTORY PREDICTORS OF DEPARTURE}

As predicted for adults, date of departure was positively correlated with date of breeding completion $(\beta=0.57$, $t_{44}=6 \cdot 0, P=<0 \cdot 001$; Fig. 2a, Table 1$)$ and age $(\beta=0 \cdot 35$, $\left.t_{44}=3.9, P=<0.001\right)$, and varied between years, being earlier in 2010 relative to 2009 (difference of mean departure date $=4 \cdot 6$ days; $\beta=-0 \cdot 62, t_{44}=-3 \cdot 3, P=0 \cdot 002$ ). Opposite to our prediction, females left significantly earlier than males (difference of mean departure date $=5.5$ days; $\left.\beta=0.68, t_{44}=3 \cdot 3, P=0.002\right)$. We found only weak evidence for an effect of body condition on date of departure ( $\beta=0 \cdot 19, t_{44}=1 \cdot 8, P=0 \cdot 082 ;$ Fig. S2a). Together, our departure date model accounted for $67 \%$ of the observed variation in timing of departure for adults.

As predicted for juveniles, date of departure was positively correlated with fledging date $\left(\beta=0 \cdot 22, t_{43}=2 \cdot 1\right.$, $P=0.040$; Fig. 2b, Table 1$)$ and body condition $(\beta=0.57$, $t_{43}=5 \cdot 3, P=<0 \cdot 001$; Fig. S2b). Similar to adults, date of departure was earlier in 2010 relative to $2009(\beta=-0.57$, $\left.t_{43}=-2 \cdot 7, P=0 \cdot 010\right)$. Together, the main effects from our departure date model accounted for approximately $56 \%$ of the observed variation in timing of departure for juveniles.

\section{WEATHER PREDICTORS OF DEPARTURE}

As predicted, adults departed under clear weather conditions: no precipitation and maximum visibility (50 of 50 observations; Fig. 3a,b) and were more likely to depart when air pressure was high $(\beta=1 \cdot 60, z=3 \cdot 0, P=0.003$; Table 2) and increasing $(\beta=3 \cdot 75, z=3 \cdot 5, P=0 \cdot 001)$. We did not find strong support for an interaction between surface wind speed and direction (Table S3); however, likelihood of
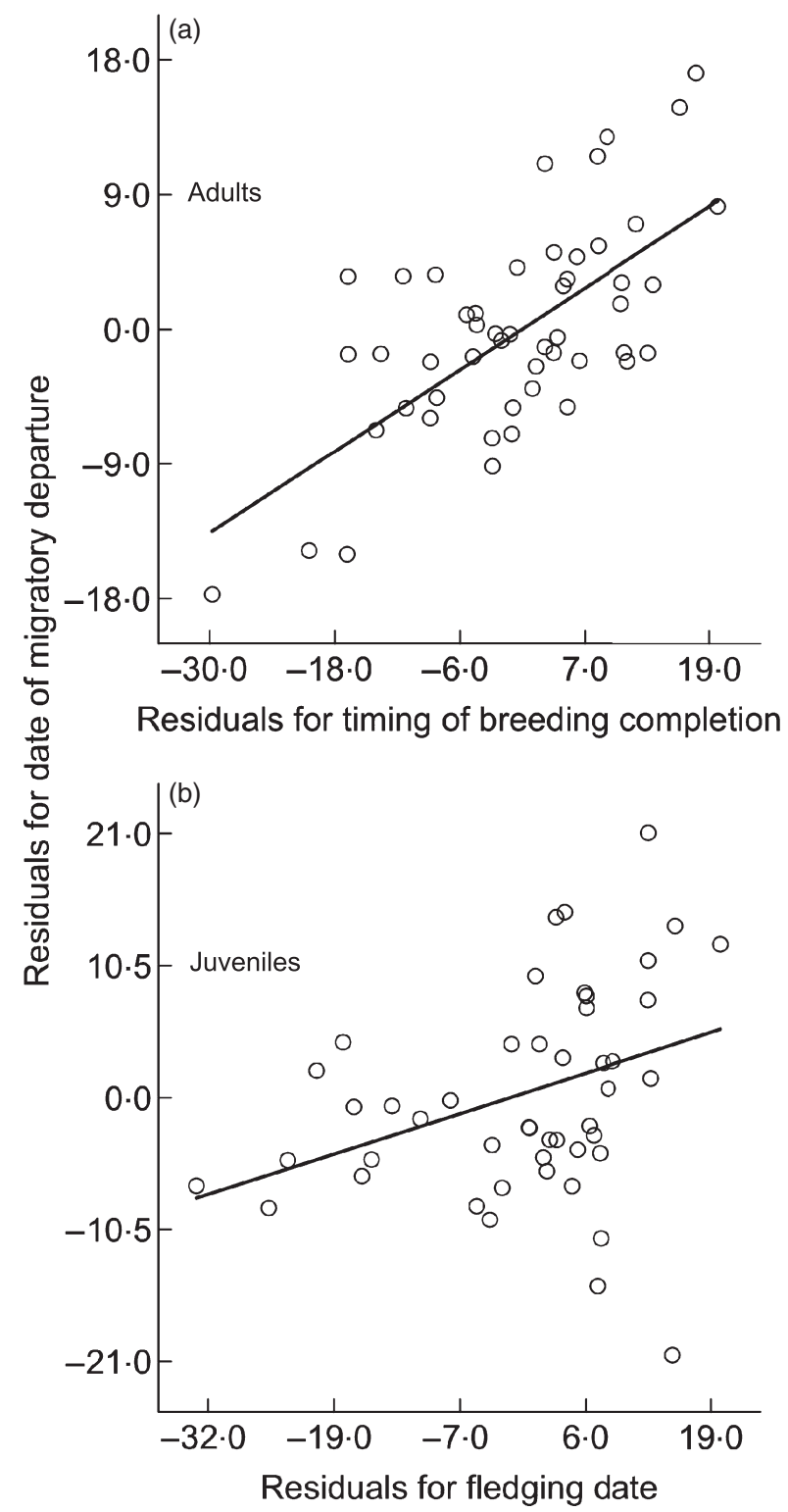

Fig. 2. Partial regression plots illustrating (a) significant positive relationship between departure date and timing of breeding completion, and (b) significant positive relationship between departure date and fledging date. Trends illustrated with locally weighted regression lines.

departure did vary with wind direction independently of wind speed; adults were less likely to depart if winds were blowing from the south as opposed to winds from the north-east $(\beta=-3 \cdot 24, z=-2 \cdot 4, P=0 \cdot 017)$, but individuals were no more or less likely to depart when winds were blowing from north-east relative to the north-west $(\beta=0 \cdot 80, z=1 \cdot 2$, $P=0 \cdot 247)$. In general, adults were more likely to depart under low wind conditions, but on one occasion, four individuals chose to depart under very high wind conditions ( $>45 \mathrm{~km} \mathrm{~h}^{-1}$; Fig. 3a). This latter group of individuals resulted in a significant convex curvilinear relationship between likelihood of departure and surface wind speed (linear term for wind speed: $\beta=-1 \cdot 32, z=-2 \cdot 6$, 
Table 1. Model results detailing the effects of ecological and life-history variables on date of migratory departure for (1) adults and (2) juveniles

\begin{tabular}{|c|c|c|c|c|c|}
\hline Model & Model term & $\beta$ & $t$ & df & $P(t)$ \\
\hline \multirow[t]{5}{*}{ (1) Date of migratory departure for adults } & Date of breeding completion & $0 \cdot 44$ & 5.96 & 44 & $<0 \cdot 001$ \\
\hline & Body condition upon departure & $1 \cdot 15$ & 1.78 & 44 & 0.082 \\
\hline & Age & $2 \cdot 91$ & $3 \cdot 85$ & 44 & $<0.001$ \\
\hline & Sex: males & $6 \cdot 22$ & $3 \cdot 30$ & 44 & 0.002 \\
\hline & Year: 2010 & $-5 \cdot 65$ & 1.78 & 44 & $0 \cdot 082$ \\
\hline \multirow{3}{*}{ (2) Date of migratory departure for juveniles } & Fledging date & $0 \cdot 21$ & $2 \cdot 12$ & 43 & $0 \cdot 040$ \\
\hline & Body condition upon departure & $4 \cdot 30$ & $5 \cdot 35$ & 43 & $<0.001$ \\
\hline & Year: 2010 & $-6 \cdot 73$ & $-2 \cdot 70$ & 43 & $0 \cdot 010$ \\
\hline
\end{tabular}

Parameter estimates are for un-standardized data.

(a)

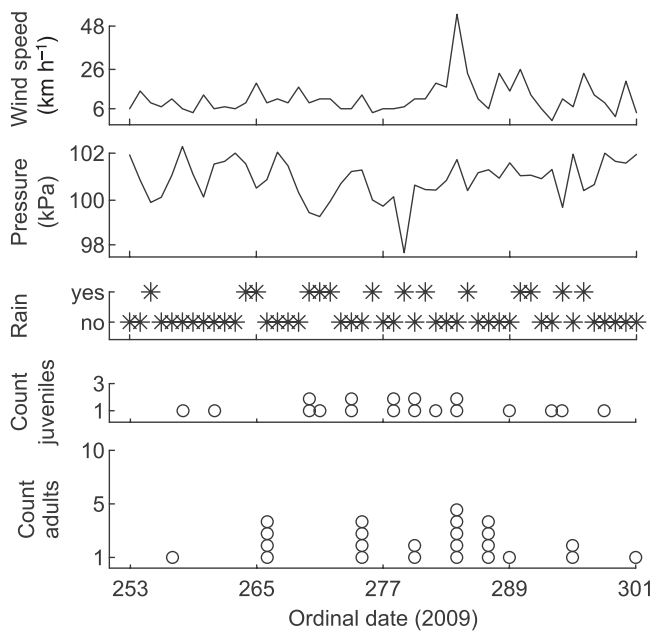

(b)

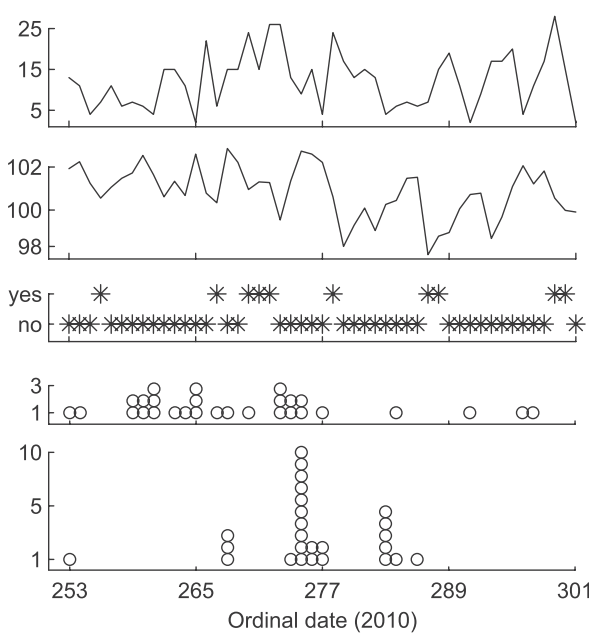

Fig. 3. Weather variables used and avoided in (a) 2009 and (b) 2010. Panels represent (from top to bottom), wind speed ( $\mathrm{km} \mathrm{h}^{-1}$ ), atmospheric pressure $(\mathrm{kPa})$, and presence or absence of precipitation $2 \cdot 1 \mathrm{~h}$ following sunset, as well as the total number of juveniles and adults departing each evening. In the bottom two panels, each circle represents one individual. The ordinal dates of 253 and 301 represent 11 September and 29 October, respectively.

$P=0 \cdot 010 ;$ curvilinear term for wind speed: $\beta=0 \cdot 49$, $z=3 \cdot 1, P=0 \cdot 002)$. We also found weak evidence for an interaction between surface wind speed and date, where individuals became increasingly less likely to depart under high wind conditions as date progressed $(\beta=-1 \cdot 00, z=-1 \cdot 8$, $P=0 \cdot 070)$. Last, and opposite to our prediction, controlling for all other main and interaction effects, individuals were more likely to depart as cloud cover increased $(\beta=2 \cdot 78$, $z=2 \cdot 8, \quad P=0 \cdot 005)$; however, cloud cover was fairly strongly correlated with decreases in pressure $(r=0.67)$, and when the effect of cloud cover is modelled on its own, the sign of the effect is in the predicted direction $(\beta=-0.96$, $z=-2 \cdot 6, P=0 \cdot 010)$; therefore, this result should be interpreted with caution. Together, the main effects in our weather model for adults accounted for $65 \%$ of the observed variation in the likelihood of departure.

Juveniles were much less choosey about weather conditions during departure than adults. Unlike adults, juveniles departed under rainy conditions (seven of 47 individuals; Fig. 3a,b), when visibility was less than maximum (11 individuals) and when winds were blowing from the south (17 individuals; Fig. 1). However, despite observations of some individuals departing in the rain, overall, juveniles tended to avoid departing during rainy evenings $(\beta=-1.96$, $z=-2 \cdot 2, P=0 \cdot 028$; Table 2$)$. Similar to adults, we did not find strong evidence for an interaction between surface wind speed and direction (Table S3), individuals did not prefer winds from the north-east relative to the north-west (main effect: $\beta=1 \cdot 37, z=1 \cdot 8, P=0 \cdot 068$; interaction effect with date: $\beta=0.68, z=0.8, P=0.426$ ), and juveniles were more likely to depart when atmospheric pressure was high ( $\beta=0 \cdot 91, z=2 \cdot 0, P=0 \cdot 050)$. However, different from adults, juveniles readily departed when winds were blowing from the south and the strength of this effect increased with departure date (main effect for winds from south-west: $\beta=1 \cdot 17, z=1 \cdot 7, P=0 \cdot 092$; interaction effect with date: $\beta=1 \cdot 48, z=2 \cdot 3, P=0.023$; main effect for winds from south-east: $\beta=-4 \cdot 13, z=-1 \cdot 7, P=0 \cdot 090$; interaction effect with date: $\beta=5 \cdot 59, z=3 \cdot 1, P=0 \cdot 002$ ), individuals did not respond to changes in atmospheric pressure $(\beta=-0 \cdot 09, z=-0 \cdot 19, P=0 \cdot 847)$, there was no effect of wind speed on likelihood of departure (linear term for wind 
Table 2. Model results detailing the effects of weather variables on the likelihood of departure for (1) adults and (2) juveniles

\begin{tabular}{|c|c|c|c|c|}
\hline Model & Model term & $\beta$ & $z$ & $P(z)$ \\
\hline \multirow[t]{8}{*}{ (1) Likelihood of departure for adults } & Surface wind speed $\left(\mathrm{km} \mathrm{h}^{-1}\right)$ & $10 \cdot 57$ & 1.66 & $0 \cdot 096$ \\
\hline & Surface wind speed $\left(\mathrm{km} \mathrm{h}^{-1}\right)^{\mathrm{a}}$ & 0.09 & $3 \cdot 12$ & 0.002 \\
\hline & Surface wind direction: from north-west & $0 \cdot 80$ & $1 \cdot 16$ & $0 \cdot 247$ \\
\hline & Surface wind direction: from south & $-3 \cdot 24$ & $-2 \cdot 40$ & $0 \cdot 017$ \\
\hline & Atmospheric pressure $(\mathrm{kPa})$ & $1 \cdot 80$ & $3 \cdot 01$ & 0.003 \\
\hline & Change in atmospheric pressure: increase & $3 \cdot 75$ & $3 \cdot 46$ & $0 \cdot 001$ \\
\hline & Cloud cover: overcast & $2 \cdot 77$ & $2 \cdot 80$ & $0 \cdot 005$ \\
\hline & Surface wind speed $\mathrm{X}$ date & $-0 \cdot 04$ & $-1 \cdot 81$ & $0 \cdot 070$ \\
\hline \multirow[t]{13}{*}{ (2) Likelihood of departure for juveniles } & Surface wind speed $\left(\mathrm{km} \mathrm{h}^{-1}\right)$ & $-0 \cdot 25$ & $-1 \cdot 17$ & $0 \cdot 240$ \\
\hline & Surface wind speed $\left(\mathrm{km} \mathrm{h}^{-1}\right)^{\mathrm{a}}$ & $0 \cdot 01$ & $0 \cdot 97$ & $0 \cdot 332$ \\
\hline & Surface wind direction: from north-west & $-12 \cdot 59$ & $-0 \cdot 73$ & $0 \cdot 465$ \\
\hline & Surface wind direction: from south-east & $-118 \cdot 80$ & $-3 \cdot 01$ & $0 \cdot 003$ \\
\hline & Surface wind direction: from south-west & -29.09 & $-2 \cdot 22$ & $0 \cdot 027$ \\
\hline & Atmospheric pressure $(\mathrm{kPa})$ & $1 \cdot 15$ & 1.96 & $0 \cdot 050$ \\
\hline & Change in atmospheric pressure: increase & -0.09 & $-0 \cdot 19$ & $0 \cdot 847$ \\
\hline & Precipitation: yes & -1.96 & $-2 \cdot 20$ & $0 \cdot 028$ \\
\hline & Cloud cover: overcast & $-0 \cdot 31$ & -0.62 & 0.537 \\
\hline & Visibility: maximum & $-2 \cdot 00$ & $-1 \cdot 90$ & 0.058 \\
\hline & Surface wind direction: from north-west $\mathrm{X}$ date & 0.05 & $0 \cdot 80$ & $0 \cdot 426$ \\
\hline & Surface wind direction: from south-east $\mathrm{X}$ date & $0 \cdot 42$ & $3 \cdot 05$ & $0 \cdot 002$ \\
\hline & Surface wind direction: from south-west $\mathrm{X}$ date & $0 \cdot 11$ & $2 \cdot 28$ & 0.023 \\
\hline
\end{tabular}

Parameter estimates are for un-standardized data. ${ }^{2}$ Refers to curvilinear term and ' $\mathrm{X}$ ' indicates an interaction. Note: a main effect for date cannot be estimated because this variable is constant across an individual's choice set (referred to as a matching variable: Hosmer \& Lemeshow 2000).

speed: $\beta=-0 \cdot 36, z=-1 \cdot 2, P=0 \cdot 213$; curvilinear term for wind speed: $\beta=0 \cdot 07, z=1 \cdot 0, P=0 \cdot 332$ ), and we found no evidence for an effect of cloud cover on the likelihood of departure $(\beta=-0.31, z=-0.62, P=0.537)$. Last, and opposite to our prediction, we found weak evidence for a negative effect of visibility on the likelihood of departure ( $\beta=-2 \cdot 00, z=-1 \cdot 9, P=0 \cdot 058)$. Together, the main effects in our weather model for juveniles accounted for $27 \%$ of the observed variation in the likelihood of departure.

\section{COMBINING ECOLOGICAL AND WEATHER DATA}

The $R^{2}$ value for the regression of observed dates of departure with predicted dates of departure after having accounted for weather for adults was $95 \%$ (Fig. 4a). Our bootstrapping procedure indicated that an $R^{2}$ value greater or equal to this was extremely unlikely by chance $(P<0.001$; three of 10000 iterations; Fig. 4a: inset). For juveniles, the $R^{2}$ value for the regression of observed dates of departure with predicted dates of departure after having accounted for weather was $89 \%$ (Fig. 4b), but different from adults, a value greater or equal to this was not statistically different from what we would expect had we randomly chosen a departure day in each individual's choice set $(P=0 \cdot 181 ; 1810$ of 10000 iterations; Fig. 4b: inset).

\section{Discussion}

We provide the first direct evidence that the timing of events on the breeding grounds carries over to affect the timing of autumn migration in both free-living adult and juvenile song- birds. While previous studies on captive birds (Pulido et al. 2001; Gwinner \& Helm 2003; Pulido \& Widmer 2005; Gwinner 2008) provide evidence for a relationship between the timing of migration and the timing of breeding, they do not include environmental variability (e.g. weather conditions, resource abundance, etc.) that could potentially mask any relationship under natural conditions. Moreover, field studies investigating the relationship between the timing of breeding events and the timing of migration have used indirect methods to measure timing, primarily at stopover sites (Ellegren 1990; Sokolov 2000; Bojarinova, Rymkevich \& Smirnov 2002). Specifically, individuals captured at the stopover sites were not the same individuals for which breeding was monitored and relationships were assessed across years, meaning that individual decisions or circumstances involving the timing of events during the breeding period cannot be directly related to the timing of migration. In contrast, our approach using detailed breeding and natal histories and automated tracking methods provides strong evidence that the timing of breeding events influences date of departure in a wild population.

To our knowledge, only one other study to date has attempted to relate the timing of breeding events to the timing of migration in individual songbirds with known breeding and natal histories. Morton \& Pereyra (1994) used fat scores and date of last capture at a trap-line to estimate departure date. However, in contrast with our results, evidence for a relationship between fledging date and departure date was not found, and low sample sizes did not allow for an assessment of the relationship between date of departure and date of breeding completion. Also, passive capture methods 


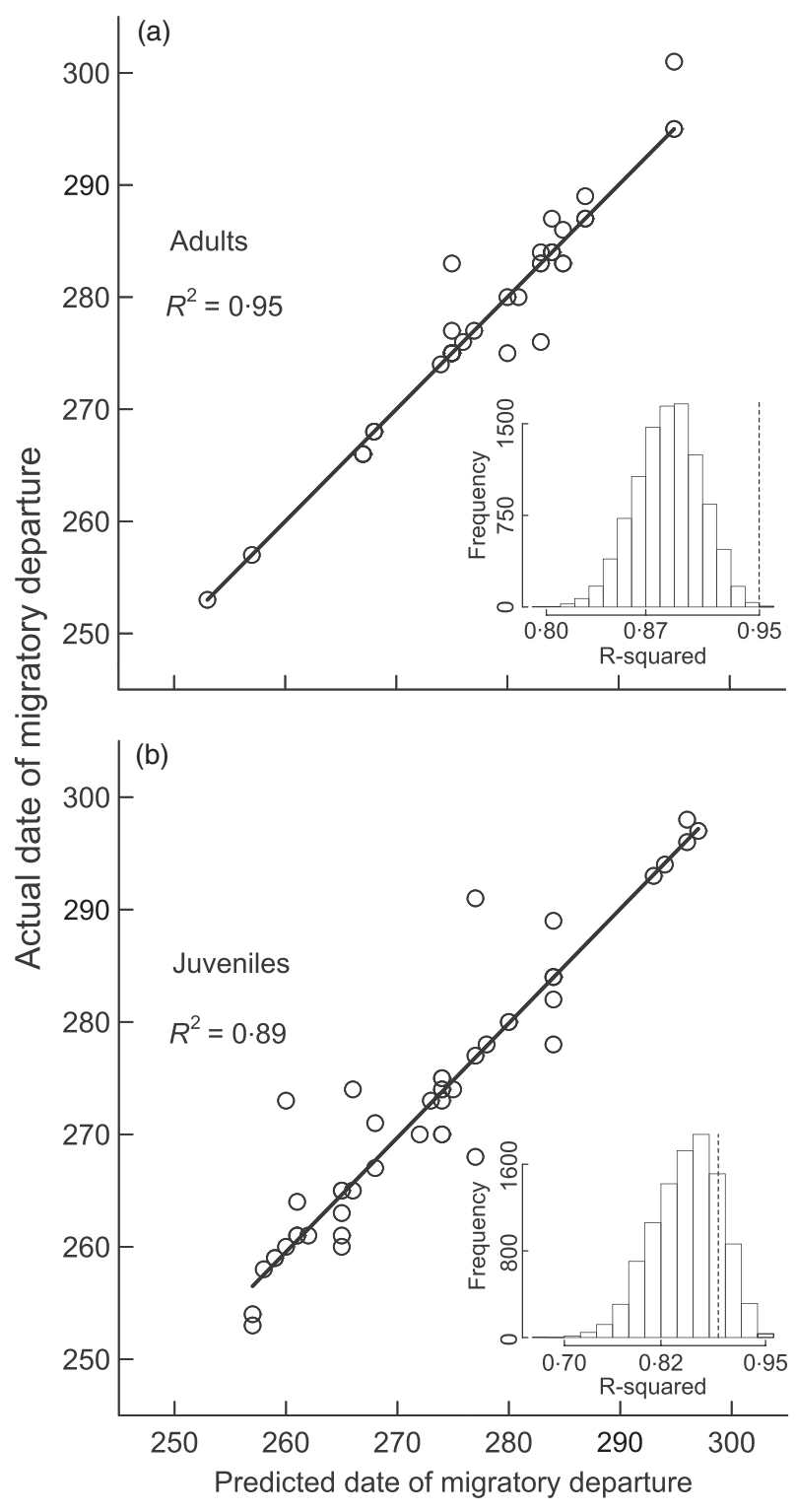

Fig. 4. Regression of actual departure dates on predicted departure dates for (a) adults and (b) juveniles. Inset histograms: probability distributions for $R^{2}$ values when departure dates are randomly selected from each individual's choice set (10 000 iterations). Hatched line in each inset histogram represents the $R^{2}$ value from the regression between observed departure dates and those predicted after accounting for breeding or natal history and weather.

generally underestimate departure dates and add noise to analyses (Schaub et al. 2001), which might partly explain why a relationship between fledging date and timing of migration was not found. Alternatively, departure from the study site may not have reflected migration, but instead, broad-scale pre-migratory movements (Vega Rivera et al. 1998). In contrast, by measuring departure directly from an isolated island, we can be confident that departures represent migratory departures and we avoid any issues with sample sizes and bias associated with passive capture methods.

Life-history theory predicts trade-offs between time and energy invested in breeding and subsequent survival. To date, several studies have identified negative correlations between survival and date of breeding completion in adults (Nilsson \& Svensson 1996; Hemborg 1999), and between first-year survival and fledging date in juveniles (Møller 1994; Shutler et al. 2006; Mitchell et al. 2011). We suggest that delayed departure represents a proximate mechanism linking the timing of events during breeding with annual survival. Specifically, late departing individuals may experience increasingly inclement weather on the breeding grounds or during migration, and may experience diminished resources at stopover sites owing to suppression by earlier migrants (reviewed by Newton 2006, 2008). Because migration is energetically demanding (Wikelski et al. 2003; Bowlin, Cochran \& Wikelski 2005), increased energy expenditure or decreases in resource intake may result in increased mortality en route (Newton 2006, 2007).

We observed females departing before males, and in one year, juveniles departing before adults. This is the first direct evidence for differential timing of migration from the breeding grounds among sex and age classes in a migratory songbird. Several hypotheses may account for these patterns. Differences in timing may reflect differences in the ability of individuals to cope with poor weather in the fall. In our population, males are larger than females, and adults are larger juveniles (Wheelwright \& Rising 2008), thus, smaller birds may depart earlier because they are less able to cope with poor weather (Ketterson \& Nolan 1976; Brown \& Brown 1998). Differences in timing might also reflect differences in competitive ability on the breeding grounds or at stopover sites (Terrill 1987), if, for example, males can outcompete females and if adults can outcompete juveniles (Ketterson 1979; Piper \& Wiley 1989). This hypothesis is also supported by our observation of younger adults departing before older adults, as adult age can also be positively correlated with social dominance (Piper \& Wiley 1989). Alternatively, differences in the timing of departure may reflect differences in wintering latitude between age and sex classes (Ketterson \& Nolan 1976). For example, males might leave later than females and adults after juveniles if they do not need to migrate as far to their wintering grounds. Last, differences in timing between age groups may reflect differences in the duration of moult (Newton 2008); juveniles are only moulting their body feathers, while adults are replacing body and flight feathers, suggesting that departure dates for adults might be constrained by the completion of moult. However, this mechanism cannot be invoked to explain differences in timing between sexes, as moult schedules are similar in each sex (Mitchell et al. 2012).

We found a positive relationship between our estimate of condition at departure and timing of migration in juveniles, suggesting that juveniles leaving early are in lower body condition than juveniles departing later in the season. A similar pattern between condition and timing of migration has been found in several other species at stopover sites - late migrating individuals have greater fat reserves (Ellegren 1991; Bairlein 1998; Izhaki \& Maitav 1998; Hedenström 2004). Whether this pattern reflects greater migration distances for 
late departing individuals, selection for greater migration speeds late in the season (sensu Newton 2008; although see Bairlein 2001), an insurance policy against increasingly inclement conditions, or is simply an artefact of having more time to accumulate fat reserves on the breeding grounds prior to departure has not been explicitly tested. Regardless, it suggests that overall migration speed will be faster for late departing juveniles, as they will likely have to stopover less frequently or for shorter durations while refuelling (Wikelski et al. 2003; Newton 2008).

Departure date of songbirds from the breeding grounds may be controlled by several proximate mechanisms operating at different temporal scales. At the broadest scale, evidence suggests that the timing of migration is controlled by a heritable endogenous mechanism (Pulido et al. 2001; Gwinner \& Helm 2003; Pulido \& Widmer 2005; Gwinner 2008). At a slightly finer scale, life-history decisions for adults and early-life circumstances for juveniles may determine the approximate time an individual will be ready to depart. At the finest scale, the availability of favourable weather conditions for migration may determine exact departure dates from the breeding grounds. In accordance with this general framework, we found that the variance in date of departure that could not be accounted for by individual life histories could be almost entirely accounted for by weather in adults, but not juveniles. Departure during favourable weather may have many benefits, such as reduced energy expenditure, increased migration rate and reduced mortality risk (Richardson 1978; Alerstam 1979; Liechti \& Bruderer 1998; Bowlin \& Wikelski 2008). It is therefore curious that juveniles depart under what appear to be relatively poor weather conditions and suggests migration under such conditions is not costly in Savannah sparrows, juveniles are able to mitigate any adverse negative effects or migration under poor weather conditions is less costly then remaining on the breeding grounds.

During their first autumn migration, juvenile migrants of many species have been shown to rely on different orientation mechanisms and to have less developed navigational abilities relative to adults (e.g. Thorup et al. 2003, 2007). It follows then, that adults and juveniles may use a different set of rules when selecting weather conditions for departure. We found that adults were much more choosey about certain weather conditions relative to juveniles. Adults but not juveniles avoided winds with any southerly component and did not depart during rainy evenings or when visibility was low. These differences may reflect adults choosing to depart only during the onset and up to the middle of high-pressure systems (light winds from the north, high and increasing pressure), while juveniles were choosing to depart throughout high-pressure systems, including the backside of the high-pressure systems as warm fronts were approaching (light to moderate southerly winds, precipitation; Richardson 1978; Cochran \& Wikelski 2005). This would explain why we observed seven juveniles departing under rainy conditions, why juveniles were departing with southerly winds, why juveniles did not respond to changes in atmospheric pressure and why departure dates for juveniles were less clumped in time relative to adult departures.

Our results also suggest that juveniles were more willing to take risks later in the season relative to adults. Specifically, juveniles were more likely to depart when winds were blowing from the south (poor weather; see above) as date progressed, again suggesting that the costs of departing under unfavourable weather conditions outweigh the costs of remaining on the breeding grounds or that late departing individuals are better able to mitigate the costs of doing so (e.g. late departing juveniles are fatter and may be better able to mitigate any energetic cost of flying into a head wind). In contrast, adults appeared to become more choosey later in the pre-migratory period with respect to wind; individuals were less likely to depart as wind speed increased later in the season. If the risk of being blown off course increases with wind strength, perhaps greater time constraints late in the fall make it difficult to mitigate additional delays or energy expenditure associated with being blown off course.

The organization of the annual cycle of migratory vertebrates suggests that life-history trade-offs or circumstances affecting the timing of events in one life-history stage (sensu Jacobs \& Wingfield 2000; Wingfield 2008) may carry over and influence individual success in subsequent life-history stages. This is because the timing of each stage is relatively inflexible (Wingfield 2008), and as result, individuals have little time to mitigate effects from previous life-history stages. Our results support this hypothesis by illustrating a strong relationship between date of migratory departure with both date of breeding completion and fledging date in a free-living migratory songbird.

\section{Acknowledgements}

We thank C. Cooper-Mullin, E. Graff, M. Janssen, R. Mauck, S. Brough, E. Christiansen, B. Dossman and T. Winegard for their assistance in the field. Our gratitude is also extended to N. Wheelwright, R. Mauck and D. Gannon for access to the study site and advice in the field. Funding for this study was provided by the Natural Sciences and Engineering Research Council (DRN, CGG), the Canada Foundation for Innovation (DRN, CGG), the Ontario Research Fund (DRN, CGG), the American Ornithologist's Union (GWM), the Animal Behavior Society (GWM), Global Forest Science (GFS-18-210330; GWM), the Society of Canadian Ornithologists (GWM), the American Museum of Natural History (GWM) and the University of Guelph (DRN, GWM). This represents Bowdoin Scientific Station contribution no. 236. All procedures were approved by the Animal Care Committees at the University of Guelph and Bowdoin College in accordance with Canadian Council on Animal Care guidelines (permit number: 08R061) and met the legal requirements of the Canadian Wildlife Service (banding permit number: 10789; scientific permit number: SC2732)

\section{References}

Åkesson, S. \& Hedenström, A. (2000) Wind selectivity of migratory flight departures in birds. Behavioral Ecology and Sociobiology, 47, 140-144.

Alerstam, T. (1979) Wind as selective agent in bird migration. Ornis Scandinavica, 10, 76-93.

Bairlein, F. (1998) The European-African songbird migration network: new challenges for large scale study of bird migration. Biological Conservation of Fauna, 102, 13-27.

Bairlein, F. (2001) Results of bird ringing in the study of migration routes and behaviour. Ardea, 89, 7-19. 
Berthold, P. (1996) Control of Bird Migration. Chapman \& Hall, New York, NY.

Bojarinova, J.G., Rymkevich, T.A. \& Smirnov, O.P. (2002) Timing of autumn migration of early and late-hatched great tits Parus major in NW Russia. Ardea, 90, 401-409.

Bowlin, M.S., Cochran, W.W. \& Wikelski, M. (2005) Biotelemetry of New World thrushes during migration: physiology, energetics and orientation in the wild. Integrative and Comparative Biology, 45, 295-304.

Bowlin, M.S. \& Wikelski, M. (2008) Pointed wings, low wingloading and calm air reduce migratory flight costs in songbirds. PLoS One, 3, e2154.

Brown, C.R. \& Brown, M.B. (1998) Intense natural selection on body size and wing and tail asymmetry in cliff swallows during severe weather. Evolution, 52, 1461-1475.

Cochran, W.W. \& Wikelski, M. (2005) Individual migratory tactics of New World Catharus thrushes. Birds of Two Worlds: The Ecology and Evolution of Migration (eds R. Greenberg \& P.P. Marra). pp. 274-289. Johns Hopkins University Press, Baltimore, MD

Dänhardt, J. \& Lindtröm, A. (2001) Optimal departure decisions of songbirds from an experimental stopover site and the significance of weather. Animal Behavior, 62, 235-243.

Ellegren, H. (1990) Timing of autumn migration in Bluethroats Luscinia s. svecica depends on timing of breeding. Ornis Fennica, 67, 13-17.

Ellegren, H. (1991) Stopover ecology of autumn migrating Bluethroats Luscinia s. svecica in relation to age and sex. Ornis Scandinavica, 22, 340-348.

Freeman-Gallant, C.R. (1996) Microgeographic patterns of genetic and morphological variation in Savannah sparrows (Passerculus sandwichensis). Evolution, 50, 1631-1637.

Gwinner, E. (2008) Circannual clocks in avian reproduction and migration. Ibis, 138, 47-63.

Gwinner, E. \& Helm, B. (2003) Circannual and circadian contributions to the timing of avian migration. Avian Migration (eds P. Berthold, E. Gwinner \& E. Sonnenschein). pp. 81-96. Springer, New York, NY.

Harrison, X.A., Blount, J.D., Inger, R., Norris, D.R. \& Bearhop, S. (2011) Carry-over effects as drivers of fitness differences in animals. Journal of Animal Ecology, 80, 4-18.

Hedenström, A. (2004) Migration and morphometrics of Temminck's Stint Calidris temminckii at Ottenby, Southern Sweden. Ringing and Migration, 22, 51-58.

Hemborg, C. (1999) Sexual differences in moult-breeding overlap and female reproductive costs in pied flycatchers, Ficedula hypoleuca. Journal of Animal Ecology, 68, 429-436.

Hosmer, D.W. \& Lemeshow, S. (2000) Applied Logistic Regression, 2nd edn. Wiley, Toronto, ON.

Izhaki, I. \& Maitav, A. (1998) Blackcaps Sylvia atricapilla stopping over at the desert edge; inter- and intra-sexual differences in spring and autumn migration. Ibis, 140, 234-243.

Jacobs, J.D. \& Wingfield, J.C. (2000) Endocrine control of lifecycle stages: a constraint on response to the environment? The Condor, 102, 35-51.

Ketterson, E.D. (1979) Aggressive behavior in wintering dark-eyed juncos: determinants of dominance and their possible relation to geographic variation in sex ratio. The Wilson Bulletin, 91, 371-383.

Ketterson, E.D. \& Nolan, V. (1976) Geographic variation and its climatic correlates in the sex ratio of eastern-wintering dark-eyed juncos (Junco hyemalis hyemalis). Ecology, 57, 679-693.

Liechti, F. \& Bruderer, B. (1998) The relevance of wind for optimal migration theory. Journal of Avian Biology, 29, 561-568.

Malcolm, S.B., Cockrell, B.J. \& Brower, L.P. (1987) Monarch butterfly voltinism: effects of temperature constraints at different latitudes. Oikos, 49, 77-82.

Manly, B.F.J., McDonald, L.L., Thomas, D.L., McDonald, T.L. \& Erickson, W.P. (2002) Resource Selection by Animals: Statistical Design and Analysis for Field Studies, 2nd edn. Kluwer, Boston, MA.

Mitchell, G.W., Guglielmo, C.G., Wheelwright, N.T., Freeman-Gallant, C.R. $\&$ Norris, D.R. (2011) Early life events carry over to influence pre-migratory condition in a free-living songbird. PLoS One, 6, e28838.

Mitchell, G.W., Wheelwright, N.T., Guglielmo, C.G. \& Norris, D.R. (2012) Short and long term costs of reproduction in a migratory songbird. Ibis, 154, 325-337.

Møller, A.P. (1994) Phenotype-dependent arrival time and its consequences in a migratory bird. Behavioral Ecology and Sociobiology, 35, 115-122.

Monteith, K.L., Bleich, V.C., Stephenson, T.R., Pierce, B.M., Conner, M.M., Klaver, R.W. \& Bowyer, R.T. (2011) Timing of seasonal migration in mule deer: effects of climate, plant phenology, and life-history characteristics. Ecosphere, 2 , article 47.

Morton, M.L. \& Pereyra, M.E. (1994) Autumnal migration departure schedules in mountain white-crowned sparrows. The Condor, 96, 1020-1029.
Newton, I. (2006) Can condition experienced during migration limit the population levels of birds? Journal of Ornithology, 147, 146-166.

Newton, I. (2007) Weather-related mass-mortality event in migrants. Ibis, $\mathbf{1 4 9}$ 453-467.

Newton, I. (2008) The Migration Ecology of Birds. Academic Press, Boston, MA

Nilsson, J.-A. \& Svensson, E. (1996) The costs of reproduction: a new link between current reproductive effort and future reproductive success. Proceedings of the Royal Society of London B, 263, 711-714.

Norris, D.R. \& Marra, P.P. (2007) Seasonal interactions, habitat quality, and population dynamics in migratory birds. The Condor, 109, 535-547.

Pinheiro, J., Bates, D., Debroy, S. \& Sarkar, D. \& The R. Core Team. (2010) Linear and non-linear mixed-effects models, version 3.1-97. Available at: http://www.cran.r-project.org/package = nlme, accessed 25 January 2012.

Piper, W.H. \& Wiley, R.H. (1989) Correlates of dominance in wintering whitethroated sparrows: age, sex and location. Animal Behaviour, 37, 298-310.

Pulido, F. \& Widmer, M. (2005) Are long-distance migrants constrained in their evolutionary response to environmental change? Causes of variation in the timing of autumn migration in a blackcap $(S$. atricapilla) and two garden warbler (Sylvia borin) populations Annals of the New York Academy of Sciences, 1046, 228-241.

Pulido, F., Berthold, P., Mohr, G. \& Querner, U. (2001) Heritability of the timing of autumn migration in a natural bird population. Proceedings of the Royal Society of London B, 268, 953-959.

Pyle, P. (1997) Identification Guide to North American Birds, Part 1: Columbidae to Ploceidae. Slate Creek Press, Bolinas, CA.

R Development Core Team (2008) R: A Language and Environment for Statistical Computing. R Foundation for Statistical Computing, Vienna, Austria. Available at: http://www.R-project.org, accessed 25 January 2012.

Rae, L.F., Mitchell, G.W., Mauck, R.A., Guglielmo, C.G. \& Norris, D.R. (2009) Radio transmitters do not affect the body condition of Savannah sparrows during the fall premigratory period. Journal of Field Ornithology, 80, 419-426.

Rappole, J.H. \& Tipton, A.R. (1991) New harness design for attachment of radio transmitters to small passerines. Journal of Field Ornithology, 62, 335 337.

Richardson, W.J. (1978) Timing and amount of bird migration in relation to weather: a review. Oikos, 30, 224-272.

Sapir, N., Wikelski, M., Avissar, R. \& Nathan, R. (2011) Timing and flight mode of departure in migrating European bee-eaters in relation to multiscale meteorological processes. Behavioral Ecology and Sociobiology, 65, 1353-1365.

Schaub, M., Pradel, R., Jenni, L. \& Lebreton, J.-D. (2001) Migrating birds stop over long than usually though: an improved capture-recapture analysis. Ecology, 82, 852-859.

Scheipl, F. (2010) Exact (restricted) likelihood ratio tests for mixed and additive models, version 2.0-5. Available at: http://www.cran.r-project.org/package $=$ RLRsim, accessed 25 January 2012 .

Shutler, D., Clark, R.G., Fehr, C. \& Diamond, A.W. (2006) Time and recruitment costs as currencies in manipulation studies of the costs of reproduction. Ecology, 87, 2938-2946.

Sokolov, L.V. (2000) Spring ambient temperature as an important factor controlling timing of arrival, breeding, post-fledging dispersal and breeding success of Pied Flycatchers Ficedula hypoleuca in Eastern Baltic. Avian Ecology and Behavior, 5, 79-104

Terrill, S.B. (1987) Social dominance and migratory restlessness in the darkeyed junco (Junco Hyemalis). Behavioral Ecology and Sociobiology, 21, 1-11.

Therneau, T. \& Lumley, T. (2011) Survival analysis including penalized likelihood, version 2.36-9. Available at: http://www.cran.r-project.org/package $=$ survival accessed 25 January 2012.

Thorup, K., Alerstam, T., Hake, M. \& Kjellén, N. (2003) Bird orientation: compensation for wind drift in migrating raptors is age dependent. Proceedings of the Royal Society of London B, 270, S8-S11.

Thorup, K., Bisson, I.-A., Bowlin, M.S., Holland, R.A., Wingfield, J.C., Ramenofsky, M. \& Wikelski, M. (2007) Evidence for a navigational map stretching across the continental U.S. in a migratory songbird. Proceedings of the National Academy of Sciences, 104, 18115-18119.

Vega Rivera, J.H., McShea, W.J., Rappole, J.H. \& Hass, C.A. (1998) Pattern and chronology of prebasic molt for the wood thrush and its relation to reproduction and migration departure. The Wilson Bulletin, 110, 384 392.

Wheelwright, N.T. \& Rising, J.D. (2008) Savannah sparrow (Passerculus sandwichensis). The Birds of North America Online (ed. A. Poole), Cornell Lab of Ornithology, Ithaca, NY, Available at: http://www.bna.birds.cornell.edu/ bna/species/045, accessed 25 January 2012. 
Wheelwright, N.T. \& Schultz, C.B. (1994) Age and reproduction in Savannah sparrows and tree swallows. Journal of Animal Ecology, 63, 686-702.

Wikelski, M., Tarlow, E.M., Raim, A., Diehl, R.H., Larkin, R.P. \& Visser, G.H. (2003) Costs of migration in free-flying songbirds. Nature, 423, 704

Wingfield, J.C. (2008) Organization of vertebrate annual cycles: implications for control mechanisms. Philosophical Transactions of the Royal Society of London $B, 363,425-441$.

\section{Supporting Information}

Appendix S1. Description of digital telemetry array.

Appendix S2. Hypotheses and predictions for departure date models.

Appendix S3. Deriving body condition at departure.

Appendix S4. Hypotheses and predictions for weather models.

Fig. S1. Plot of radiotransmitter signal strength vs. time of evening for an adult male departing Kent Island on 15 October 2009.
Fig. S2. Partial regression plots illustrating relationship between body condition and departure date for (a) adults and (b) juveniles.

Table S1. Parameter estimates for variables affecting the departure date of adults when (1) including and (2) excluding one observation from two individuals measured in both years of the study.

Table S2. Parameter estimates for weather variables affecting likelihood of departure for adults when (1) including and (2) excluding one observation from two individuals measured in both years of the study.

Table S3. Likelihood ratio tests for interactions between wind speed and wind direction, as well as interactions between date and body condition with each main effect included in the weather models for (1) adults and (2) juveniles.

As a service to our authors and readers, this journal provides supporting information supplied by the authors. Such materials may be re-organized for online delivery, but are not copy-edited or typeset. Technical support issues arising from supporting information (other than missing files) should be addressed to the authors. 